\title{
Foregut Symptoms, Somatoform Tendencies and the Selection of Patients for Antireflux Surgery
}

\author{
Karl-Hermann Fuchs ${ }^{1}$, Frauke Musial ${ }^{4}$ \\ Ferdinand Ulbricht ${ }^{1}$, Wolfram Breithaupt $^{1}$, Alexander Reinisch ${ }^{1,2}$, \\ Benjamin Babic ${ }^{1}$, Hans Fuchs ${ }^{3}$, Gabor Varga ${ }^{1}$ \\ ${ }^{1}$ AGAPLESION - Markus-Krankenhaus, Department of Surgery, Academic Teaching \\ Hospital, Goethe University Frankfurt, Wilhelm-Epstein-Straße 4, 60431 Frankfurt am Main \\ ${ }^{2}$ Goethe University Frankfurt, Department of General Surgery, Frankfurt, Germany \\ ${ }^{3}$ University of Cologne, Department of General Surgery, Cologne, Germany \\ ${ }^{4}$ The National Research Center in Complementary and Alternative Medicine, UIT University \\ Tromsø, Norway
}

Address of Correspondence:

Prof. Dr. med. K.-H. Fuchs

Dept. of Surgery, AGAPLESION - Markus-Krankenhaus

Academic Teaching Hospital, Goethe University Frankfurt

Wilhelm-Epstein-Straße 4

60431 Frankfurt am Main; Germany

e-mail: Karl-Hermann.Fuchs@fdk.info

Tel: +49 699533 2212; Fax: +49699533 2679

Funding: There was no funding involved.

Conflicts of interest: The authors do not have any conflicts of interest.

Authors contribution: KHF, FM, WB and GV had substantial contributions in the study concept and design, the revision and drafting of the manuscript, analysis and interpretation of the data and statistical analysis. FU, AR, BB and HF had substantial contributions in the acquisition of the data, analysis and interpretation of data. All authors had substantial contribution in the drafting of the manuscript, revising of the manuscript and the final approval of the manuscript to be published. All authors agree to be accountable for all aspects of the work and ensuring its accuracy and its integrity. 


\section{Abstract:}

Background: A large variety of foregut symptoms can occur in patients with Gastroesophageal Reflux Disease (GERD), which can overlap with other disorders such as somatoform disorders and dyspepsia. Due to unclear diagnostic situations, these patients are often not adequately managed. Purpose of this study is the evaluation of patients with foregut symptoms, referred for possible antireflux surgery, regarding their relationship with GERD and somatization tendencies based on control data from an unselected population.

Methods: Symptom evaluation and Somatization screening were initiated both in volunteers and in patients with foregut symptoms and GERD. Unselected volunteers from a village population were also evaluated by symptom analysis and for somatisation tendency. In addition, patients with foregut symptoms were diagnosed for GERD and symptom analysis and psycho-diagnostic evaluation was performed.

Results: There is no major significant difference in the symptom-spectrum in patients with foregut symptoms, whether they have a proven pathologic acid exposure from GERD or not. The probability for the risk of somatization was 5,6 \% in the unselected population of non-patient volunteers $(n=267)$. In patients with foregut symptoms $(n=750)$, the probability for the presence of somatoform tendencies was approximately $20 \%$, independent whether these patients had a documented GERD or a normal esophageal acid exposure, implicating further diagnostic work-up for the selection of patients for antireflux surgery.

Conclusion: There is a remarkable symptom load and variety in patients with GERD, in patients with foregut symptoms and in an unselected population of volunteers. There is no difference in the risk for somatization between patients with foregut symptoms and those with documented GERD. Therapeutic decision making 
especially prior to antireflux surgery requires an awareness of mental and emotional challenges.

Key words: GERD; antireflux surgery; laparoscopic fundoplication; somatization; GERD-symptoms

\section{Introduction:}

The selection of patients for antireflux surgery is as important as a good operative technique in reaching a satisfying therapeutic outcome for the patients. The variety of symptoms in patients with possible gastroesophageal reflux disease is substantial and have to be analysed prior to considering surgery (1-7). Especially the overlap to other diseases and in particular to functional disorders bears the risk of wrong diagnoses and misinterpretations (2,4,6,8-13). In general, foregut symptoms such as epigastric pain, nausea, vomiting, belching, regurgitation, epigastric and/or retrosternal burning, swallowing discomfort or even respiratory symptoms such as hoarseness, chronic cough, pain in the throat, globus, pharyngeal, mouth and tongue burning can be related to Gastroesophageal Reflux Disease (GERD) as well as to several other diseases and pathologic conditions, which can be difficult to differentiate (1-13). A substantial part of these patients have symptoms from dyspepsia and somatoform disorders (4,8-13).

GERD has a multifactorial pathophysiologic background and its clinical presentation shows a large variety of different symptoms including heartburn, regurgitation, epigastric pain, retrosternal pressure and pain, pharyngeal burning, hoarseness, chronic cough, nausea, vomiting and dysphagia $(1,3,4,5,7,14)$. As shown in the past, heartburn and acid regurgitation are highly specific for GERD, when these are chief 
complaints of the patients $(1,2,4,6,7$,$) . However, these symptoms can show a broad$ overlap with other disorders such as functional dyspepsia, irritable bowel syndrome and somatoform disorders (8-23).

Severe GERD can be objectified by endoscopy and by functional studies such as Impedance-pH-monitoring $(4,7,24,25)$. But it remains a diagnostic dilemma in patients with borderline objective diagnostic findings in association with a large variety of unspecific foregut symptoms.

Somatization describes a situation, where in a given patient/person somatic complaints are present, which cannot be explained by pathophysiological and/or measurable findings $(4,9,10,26-31)$. Psychodiagnostic instruments are helpful in order to clarify the clinical situation and establish a diagnosis. Several tests are available to evaluate patients/persons with a suspicion of having a somatoform disorder (27-33). Very often these patients have comorbid symptoms of depression and anxiety $(33,34)$. In addition, somatoform disorders and anxiety can hamper the clinical assessment of patients $(35,36)$.

Due to this unclear diagnostic situation, these patients are often not adequately managed, since in many patients symptomatic therapy is started without further verification of the diagnostic background (37-39). Furthermore, some patients receive insufficient drug therapy or inadequate life style advise for years, and sometimes even worse, they are referred to unjustified surgical therapy, after a long, refractory drug therapy.

Even more demanding for the diagnostic situation, the quality of life can be severely impaired in these patients and consequently the subjective experience of suffering can be demanding $(7,40,41,42)$. Thus, there is a need for clearly defined criteria for 
therapeutic decision making based on sound reasoning and objective data. Especially prior to gastric or antireflux surgery, a clear diagnostic picture with proven symptom-correlation to the underlying disease is mandatory. However, little is known about the relationship between GERD and somatoform tendencies.

Therefore, the purpose of this study is the evaluation of patients with a large variety of foregut symptoms, referred to a specialized surgical unit for possible laparoscopic antireflux surgery, regarding their pathophysiologic background and their relationship to GERD and/or aspects of somatization, based on control data from an unselected population.

\section{Methods:}

In this trial, the first step was a basic evaluation of the chosen instruments for symptom evaluation in a large unselected population of non-patient volunteers. Symptom evaluation and Somatization screening were initiated both in volunteers and in patients with foregut symptoms in order to determine the possible differences.

\section{Unselected population of non-patient volunteers (Normal control group)}

For comparison, an unselected population of two villages was investigated, using questionnaires to determine the presence and the variety of their symptoms. In addition, a validated screening instrument for somatoform tendencies was applied. For that purpose, the inhabitants of the villages were informed 3 weeks prior to the questionnaire about the project. Then the instruments for the assessment of symptoms and the evaluation of somatoform disorders (27-31) were distributed. Two 
days later the questionnaires were recollected and then evaluated. Inhabitants, who were known to be currently under medical treatment or who were seeking medical help, were excluded from the analysis.

\section{Patients}

Patients with foregut symptoms and heartburn, referred to a specialized referral center of gastrointestinal functional disease during a period of 4 years, were asked for their permission and were subsequently registered in the study, as permitted by our Institutional Review Board. They entered a defined prospective protocol of assessment and investigations. All patients received standardized questionnaires to assess all presenting symptoms, a validated screening test for somatoform disorders (27-31) similar to the normal control group.

Furthermore, the protocol consisted of documentation of their medical history, physical examination, upper gastrointestinal endoscopy, standard esophageal manometry, 24h-pH-monitoring, and other selectively used investigations such as 24h-bilirubine monitoring, gastric emptying scintigraphy and radiographic barium studies in order to determine the presence of GERD or other diseases, as described earlier $(1,3,7)$.

\section{Diagnostic Investigations:}

Assessment of the variety of symptoms was performed by using the symptom-list as integrated in the instrument for the evaluation of somatoform disorders as established and validated by Rief (27-31). The SOMS-Instrument was chosen, because it provides an extended list of symptoms, which serves the purposes of this study best, as it allows to screen for a general symptom load, which provides a 
sufficient number of non-gastrointestinal symptoms, to screen for a general symptom load in patients with a suspected or known gastrointestinal disorder.

The SOMS-instrument as "screening test for somatoform disorders" has been established and validated a few years ago (27-31). Assessment for the presence of somatoform tendencies is performed by using this established instrument in the unselected healthy population and in all patients. The instrument SOMS (screening test for somatoform disorders) consists of 68 items, basically assessing the presence of the full variety of possible symptoms of the test-person.

In patients with somatoform disorders, some of these symptoms are quite frequently present $(27,28)$. The instrument covers somatic symptoms that can occur in these patients with somatoform disorders without a clear physical explanation nor prove of explainable somatic changes. This questionnaire has extensively been validated and several methods of analysis are available (27-31).

For the purpose of this study, the authors have chosen the analysis of the presence of symptoms and the presence of somatoform tendencies, using 53 items, which are basically a list of 53 symptoms (Table 1). This symptom list is easy to apply for the investigated individuals. The symptom-list can serve as basis for the determination of all symptoms. Second, by counting the number of symptoms, present in a given patient without an explanation of the underlying cause, one can determine the Somatoform Symptom Index (SSI). The latter represents the level of probability for the presence of somatoform disorder in a given patient (27). This analysis is documented in the original manual and shows for normal values a SSI of 5,1 . In the original manual (SOMS: Screening für Somatoforme Störungen) by Rief, the 
borderline value towards 99 percentile probability for the presence of somatoform disorders is a SSI of 17 symptoms (27).

All patients underwent upper gastrointestinal endoscopy, esophageal manometry, and esophageal 24-h-pH-monitoring. All data were gathered and documented prospectively. During endoscopy, the severity of esophagitis was graded according to the classification of Savary-Miller and the present size of the hiatus hernia was measured.

Standard esophageal manometry was carried out using an 8-lumen, waterperfused manometry catheter on the reclining, fasting patient. The position, pressure, and length of the lower esophageal sphincter were determined with the pull-through manometry, using these measurements for the correct positioning of the $\mathrm{pH}$-probes $5 \mathrm{~cm}$ above the upper boarder of the lower esophageal sphincter.

24h-pH-monitoring was applied in standard technique using for analysis the DeMeester-reflux-score criteria (1). This implemented a borderline between physiologic and pathologic esophageal acid exposure, if the score reached a value of 14,7. Seven days prior to the examination all medications affecting motility and acid suppression were stopped.

\section{Analyses}

Different analyses were performed on the generated data. A first analysis was made by creating an overview on the presence and variety of different symptoms in the unselected control population (symptom-analysis 1), in all patients with foregut symptoms, separated in those without pathologic reflux (symptom-analysis 2) as well as in patients with documented GERD (symptom-analysis 3). 
Secondly, the probability for the presence of somatoform tendencies was evaluated in the unselected control population, in the patient-group with foregut symptoms and in the documented GERD-patients in order to determine the differences.

Since the size of the investigated populations were rather large, the students T-test was used for the simple group comparisons. If multiple comparisons were performed such as in the analysis of symptoms, alpha-level was adjusted accordingly (for $n=53$ items in the SOMS manual adjusted $p=0.00094$ ). For the comparison of the number of patients with positive and negative DeMeester score compared to an SSI $\leq 17$ or $>17$ (contingency table) a Chi-square test was conducted. All analyses were carried out with SPSS.

\section{Results:}

\section{Characteristics of Control group:}

The unselected control-group consisted of 267 healthy inhabitants of two villages. There were 127 males and 140 females. The mean age was 44 years (Standard Deviation 1,551, range 18-84). This group of volunteers represents a country based population.

\section{Patient`s characteristics}

In a 4 year period 750 patients with foregut symptoms and heartburn were prospectively included in this study. Patients had a mean age of 49 years (16-89). There were 305 females and 445 males. The prospectively documented data showed 
at time of evaluation for this study a partial lack of data in 99 data-sets, leaving 651 complete patient data-sets (foregut-symptom group) for detailed analysis.

The patients of the foregut-symptom group $(n=651)$ had a mean age of 49 years (1886). There were 397 males and 254 females. Current presence of esophagitis was confirmed by endoscopy in 208 patients (32\%). The results of $24 \mathrm{~h}-\mathrm{pH}$-monitoring showed a positive DeMeester-reflux Score in 389 patients $(59,8 \%)$, indicating a patient-group with proven GERD. Esophagitis was present in 196 of the 389 patients $(50,4 \%)$ with documented pathologic acid exposure in the esophagus.

\section{Unselected population of non-patient volunteers:}

Figure 1 demonstrates the presence of symptoms in the control group. The volunteers showed a remarkable symptom load with a large variety such as headache, repetitive pain in joints, in the back, in arms and legs in 30 to $54 \%$. In addition, $15-20 \%$ of persons in the unselected control group had complaints about unspecific symptoms such as fullness, nausea, food intolerance, belly pain, chest pain, excessive fatigue and other unspecific troublesome body sensations.

\section{Comparison between patients and the control group:}

The classic foregut symptoms such as epigastric pain, belly pain, fullness and belching are more frequently present compared to healthy volunteers. Belly pain is present in $70 \%$ of patients, fullness in $67 \%$, belching in $72 \%$, hick-ups and burning in $69 \%$, and food intolerance in $60 \%$.

The comparison between the symptom presence in unselected volunteers and in patients with foregut symptoms demonstrate significant differences for several symptoms. The most important differences are shown in Table 2. 


\section{Comparison of symptom distribution in relation to esophageal acid exposure:}

Figure 2 demonstrates the difference in symptoms between patients with a positive and those with a negative $24 \mathrm{~h}-\mathrm{pH}-$ monitoring test, the latter indicating either a rather mild form of reflux problem or a functional dyspepsia. There was no difference in symptom presence for a number of "reflux-like" symptoms such as belching, burning and hick-ups. There were marginal significant differences for swallowing problems and epigastric pain/belly pain.

\section{The probability for the presence of somatoform disorders in health and GERD:}

In the unselected population of non-patient volunteers $(n=267)$, the Somatoform Symptom Index (SSI) was 6,4 (Standard Deviation: 5,7) (Median: 5 (0-35)), as shown in Figure 3. The borderline value between normal range for the number of presenting symptoms (total 53 items of SOMS) and the abnormal pathologic number of presenting symptoms was calculated and determined as $\mathrm{SSI}=17,8$.

Among the healthy individuals 15 out of 267 individuals had a SSI > 17, thus indicating that $5,6 \%$ of this population show a risk for a somatoform tendency, if they did not have an undiagnosed disorder. This value confirms the original data published in the SOMS-manual by Rief (27), in which they have listed normal percentage values for different percentiles. The value SSI $>17$ reflects a $99 \%$ probability of the presence of somatoform disorder. In the unselected population of non-patient volunteers, included in the study, the percentage of patients with somatoform tendency $(5,7 \%)$ was similar to the norm population in the SOMSmanual. 
Figure 3 demonstrates the SSI for the different groups of analyses. In patients with foregut symptoms ( $\mathrm{n}=651)$, the mean SSI was 11,6 (Median:11 (0-37)). This was significantly higher than in the control group, 6,4 versus $11,6 \%(p<0,001)$. In patients with documented GERD ( $n=389$ ), the mean SSI was calculated with 11,4 (Median: 11). Patients with foregut symptoms and a normal acid exposure had a mean SSI of 11,8 (Median: 11), which was quite similar to those patients with GERD.

\section{The relationship between GERD and possible somatoform tendencies in patients with foregut symptoms:}

Figure 4 demonstrates the distribution of individuals with and without somatoform tendencies in the different groups. Out of 651 patients with foregut symptoms, $n=389$ patients had proven GERD. Of these patients, 76 patients $(19,9 \%)$ showed in addition a SSI > 17, which would under the exclusion of a given, pertinent pathophysiology indicate a risk for a somatoform disorder, compared to 5,6 \% in the normal control group.

Figure 5 demonstrates this relationship between the presence of GERD based on acid exposure and the SSI. In patients with a pathologic esophageal acid exposure, $19,5 \%$ show a positive SSI (SSI >17), while patients with a normal acid exposure have in $20,6 \%$ a positive SSI. The Chi2 - Test was not significant $(p=0,679))$. In addition, the 12 patients with esophagitis and a normal esophageal acid exposure did show a similar relation between SSI-positive and SSI negative individuals in SSI>17. This indicates that there was no statistical connection between acid exposure and a measure for somatoform tendencies, the SSI in a group of patients with GERD, and thus a high symptom load. 
In summary, the results of this study show a remarkable variety of symptoms in healthy volunteers and in patients seeking help because of their foregut symptoms. There is no major significant difference in the symptom-spectrum in patients with foregut symptoms, whether they have a proven pathologic acid exposure from GERD or not.

The probability for the risk of somatization as indicated by a SSI $>17$ was as high as $5,6 \%$ in the unselected population of non-patient volunteers. In patients with foregut symptoms, the probability for the presence of somatoform tendencies was approximately $20 \%$, independent whether these patients had a documented GERD or a normal esophageal acid exposure. Furthermore a high risk for somatization can be likewise present in patients with foregut symptoms with and without proven GERD.

\section{Discussion:}

This work was stimulated by the diagnostic dilemma regarding patients with a large variety of foregut symptoms, seeking for medical help and possible antireflux surgery to receive relief from their symptoms. The vast majority of these patients are usually ex juvantibus treated by antisecretory medication. With limited therapeutic success of their medication, these patients quite often find their way to antireflux surgery. The particular strength of the data presented here are i) the defined prospective protocol of assessment and investigations and ii) the unselected control population. Both populations were measured with the same questionnaires thus allowing for a direct comparison. This is insofar new as it enables a direct comparison between the 
situation in the GP's office and the reality of a tertiary specialist care center with regard to GERD symptoms and somatoform tendencies. To our knowledge, no such data are available to date.

Symptoms, originating in the foregut, can have a large variety, as demonstrated again in this study. If the symptom load is high and includes a number of symptoms from different systems (e.g. gastrointestinal and cardiovascular), patients may also suffer a risk for the presence of a somatoform or, as recently defined, a somatic symptom disorder $9,10,23,27,30)$.

Symptoms, caused by GERD, can also vary substantially $(1,2,4,5,7,14)$. These symptoms can be differentiated in typical symptoms, such as heartburn and/or regurgitation $(2,4,6,7)$ and rather unspecific gastrointestinal symptoms are epigastric pain, nausea and vomiting, belching and chest pain $(2,4,7)$.

Heartburn in patients with pathologic acid reflux is present in $72-99 \%(1-3,4,5,6,7$, 14). Heartburn can be also present in 6-20 \% of dyspepsia patients $(6,12-19,21-23)$. However, there are controversial reports regarding the correlation between functional testing and symptoms, which makes precise diagnosis difficult based on symptoms $(2,4,7,17,20,37-39)$. However, the presence of heartburn and regurgitation in patients with GERD does have a positive prognostic value regarding the outcome of a potential antireflux operation (43).

Regurgitation is also one of the most important symptoms in GERD with a prevalence of $33-86 \%(1,2,3,4,7,44)$. Epigastric pain is present in patients with foregut symptoms in $70 \%$, in those with documented pathologic acid reflux in 12 - 67 \%. The overlap with dyspepsia and somatoform disorders is large (1-20). 
Extraesophageal symptoms such as cough, hoarsness, globus and breathing problems can be associated with syndromes such as Reflux cough syndrome and with laryngitis and asthma (4,7,45-52).

In this study, the diagnosis of GERD in the "foregut patients" was established based on the traditional diagnostic workup with clinical evaluation, endoscopy and functional testing including ph-monitoring to determine the esophageal acid exposure $(1,3)$. This was done with intention to verify undoubtedly the presence or absence of the disease. One could argue that esophagitis-positive is enough proof of GERD and no further diagnostic testing is necessary (6). The diagnostic value of the presence or absence or the grading of esophagitis is limited by the unknown effect of protonpump-inhibitor therapy, which can not be assessed accurately in such a patient population. The authors felt that for the purpose of this study, a clear separation criterion was needed, which could be best served by the acid exposure as measured by $24 \mathrm{~h}-\mathrm{pH}$-monitoring. This would allow for a sharp discrimination line between physiologic and pathologic acid exposure $(1,3,7)$.

The authors have chosen the SOMS instrument of Rief, because this instrument is validated extensively and its applicability is possible in all patients (27-31). The SOMS instrument covers a large variety of symptoms, including also physical symptoms, which many patients with foregut problems do have. The latter is important to have a common pool of symptoms covering the aspect of somatization and GERD. For the comparison of the data with GERD-patients the authors wanted to include as many symptoms in the total assessment as possible to make sure that all possible reflux associated symptoms would be integrated in the analysis. 
A central criterion for the diagnosis of somatoform disorders has been the exclusion of a somatic disorder, that can explain the symptom pattern $(27-29,36)$. However, this has been a major challenge in the diagnostics of somatoform disorders, since patients can very well have pathological findings, which, however, do not explain the extent of their symptom load or the suffering associated with it. Therefore, this demand has been substantially weakened in the very recent Diagnostic and Statistical Manual of Mental disorders (DSM-5) and the syndrome has recently been renamed to "somatic symptom disorder" (36). However, since the data collection and the whole rationale of the study is based of the former definition of the DSM IV, the terminology of somatoform disorder can be used.

Nonetheless, the current redefinition sheds light on the implicit challenge to establish an appropriate procedure with the goal to achieve a good diagnostic process, which takes all aspects of the patients suffering into account: the "objective" pathophysiological measures, and the subjective suffering associated with the symptom load. Thus, the establishment of a precise diagnosis based on symptom analysis in patients with foregut symptoms with the aim to differentiate between GERD and functional dyspepsia, while at the same time taking the aspect of somatization into account, is challenging $(8,16,17,20)$.

If the symptom load in GERD was exclusively related to pathologic acid exposure, then it could have been expected that patients with high symptom load and a negative DeMeester score would show a higher risk for somatization. However, this was not the case.

The data suggests that there is no correlation between the symptoms and the objective data of esophageal acid exposure as well as the tendency for a somatoform 
disorder, which irritates on first sight. However, this was shown in the statistical comparison with parametric tests using large groups. In addition, also nonparametric tests (Spearman-Rho) were performed indicating that both showed no significant correlation. Considering the size of the volunteer population and the patient population, it can be concluded that indeed the presence of symptoms does not correlate to the objective functional data.

In conclusion, these findings do imply that in the case of GERD, somatoform tendencies as indicated by a SSI > 17 can well be associated with pathological reflux. These findings emphasize the usefulness of the redefinition of the concept of somatoform disorders, as expressed in the DSM-5 $(27,36)$. Indirectly, this present study and its control group reproduces and thus confirms the original data published in the SOMS-manual by Rief, in which they have listed normal percentage values for different percentiles (27). The value of more than 17 symptoms for the SSI reflects a 99\% probability of the presence of somatoform disorder in the original validation, which corresponds exactly to the result of the control population in this study.

A number of studies have been performed with similar intention $(10,32,36,37,38,53-$ 56). Other instruments are the symptom-check-list SCL-90-R and the HypochondrieScale MMPI, which evaluate fewer symptoms and are therefore more restricted $(10,27,53,54)$. Another instrument is the "Othmer and de Souza Screening Test" for somatoform disorders $(55,56,57)$. The latter has been also criticized for the limited number of symptoms. With the SCAN-Test (Schedules for Clinical Assessment in Neuropsychiatry) $19 \%$ of patients within an investigated population was detected with signs for somatoform disorders, which reflects a similar portion of patients as in our current study population (57). 
In a study from Australia, 340 family doctors were involved, using the Kessler Psychological Distress Scale, the Whiteley Index and the 15-item Patient Health Questionaire (PHQ-15) on their patients (10). In 10507 patients, 18,5\% were identified as "somatizer", thus suffering from somatoform tendencies.

Again, it is quite interesting that the portion of patients with signs of somatoform disorders, is reported in different studies at the level around $20 \%$ in several patient populations with different disease entities. As detected in this study with GERD patients, the portion of patients with signs of somatization was also around $20 \%$.

\section{Conclusions:}

In conclusion, the results of this study show a number important facts:

There is a remarkable symptom load and variety in patients with foregut symptoms and more specific in patients with documented GERD. The portion of patients, who are at risk for a somatisation disorder was around $20 \%$. There is no difference in the risk for somatization between patients with foregut symptoms and those with documented GERD.

There is also a substantial variety of symptoms in an unselected population of nonpatient volunteers. A reasonably high proportion of these study participants $(5,6 \%)$ would be classified as being at risk for a somatoform disorder, if they did not suffer from a confirmed somatic disease.

Based on these findings, our study has important clinical implications for the future, which can be concluded as follows: Symptoms are not a reliable guide in these functional disorders to verify the diagnosis alone, especially in GERD. Functional testing is essential for a precise diagnosis or exclusion of GERD and subsequent 
therapeutic decision making. If in the diagnostic process, a risk for a somatoform symptom disorder is perceived, a further clinical psycho-diagnostic evaluation is recommended. An accurate process of therapeutic decision making especially prior to antireflux surgery in all patients with multiple and complex foregut symptoms, requires not only a thorough investigation of the somatic pathophysiology, but in addition an awareness of the mental and emotional challenges, many patients with a high symptom load have. These aspects are of utter importance for the clinical prospects of the individual patient and should also have an impact on patient informed consent prior to the decision making for any long term treatment and antireflux surgery.

\section{Disclosures:}

All authors declare that they have nothing to disclose. 
- 20 - 


\section{References:}

1. DeMeester TR. Definition, detection and pathophysiology of gastroesophageal reflux disease. In: International trends in general thoracic surgery, vol.3 ed DeMeester TR, Matthews HR. Benign esophageal disease. Mosby St. Louis,1987; 99-127.

2. Klauser AG, Schindlbeck NE, Müller-Lissner SA. Symptoms in gastro-esophageal reflux disease. Lancet 1990; 335: 205-208.

3. Fuchs $\mathrm{KH}$, Freys SM, Heimbucher J, Fein M, Thiede A: Pathophysiologic spectrum in patients with gastroesophageal reflux disease in a surgical $\mathrm{GI}$ function laboratory. Diseases of the Esophagus 1995, 8: 211-217.

4. Vakil N, van Zanten SV, Kahrilas PJ, Dent J, Jones R, and the global consensus Group. The Montreal Definition and Classification of GERD: a global Evidence-based Consensus. Am J Gastro, 2006; 101:1900-1920.

5. Malfertheiner $\mathrm{P}$, Nocon M, Vieth $\mathrm{M}$ et al. Evolution of gastrooesophageal reflux disease over 5 years under routine medical care - the ProGERD study. Aliment Pharmacol Ther. 2012 Jan; 35 (1): 154-64.

6. Costantini M, Crookes PF, Bremner RM et al. Value of physiologic assessment of foregut symptoms in a surgical practice. Surgery 1993, 114, (4): 780786.

7. Fuchs $\mathrm{KH}$, Babic B, Breithaupt $\mathrm{W}$ et al. EAES recommendations for the management of Gastroesophageal reflux Disease, Surg Endosc 2014; 28: 17531773.

8. Holtmann G, Kutscher SU, Haag S et al. Clinical presentation and personality factors are predictors of the response to treatment in patients with functional dyspepsia; a randomized, double-blind placebo-controlled crossover study. Dig Dis Sci. 2004 Apr;49(4):672-9.

9. Koloski NA, Boyce PM, Talley NJ: Somatization an independent psychosocial risk factor for irritable bowel syndrome but not dyspepsia: a population-based study. Eur J Gastroenterol Hepatol. 2006 Oct;18(10):1101-9.

10. Clarke DM, Piterman L, Byrne CJ, Austin DW: Somatic symptoms, hypochondriasis and psychological distress: a study of somatisation in Australian general practice. Med J Aust. 2008 Nov 17;189(10):560-4.

11. Clauwaert N, Jones MP, Holvoet L, Vandenberghe J, Vos R Tack J, Van Oudenhove L. Associations between gastric sensrimotor function, depression, somatisation and symptom-based subgroups in functional gastroduodenal disorders: are all symptoms equal ? Neurogastroenterol Motil 2012; 24(12): 1088. 
12.

Bradley LA, Richter JE, Pulliam TJ et al. The relationship between stress and symptoms of gastroesophageal reflux: the influence of psychological factors. Am J Gastroenterol. 1993; 88(1):11-9

13.

Johnston BT, Lewis SA, Love AH: Stress, personality and social support in gastro-oesophageal reflux disease. J Psychosom Res. 1995; 39(2):221-6.

14. Lord RVN, DeMeester SR, Peters JH et al. Hiatal Hernia, Lower Esophageal Sphincter Incompetence, and Effectiveness of Nissen Fundoplication in the Spectrum of Gastroesophageal Reflux Disease; J Gastrointest Surg 2009, 13:602-610.

15.

Baker LH, Lieberman D, Oehlke M: Psychological distress in patients with gastroesophageal reflux disease. Am J Gastroenterol. 1995; 90(10):1797-1803.

16. Johnston BT, Gunning J, Lewis SA: Health care seeking by heartburn sufferers is associated with psychosocial factors. Am J Gastroenterol. 1996; 91(12):2500-4.

17.

Tack J, Caenepeel P, Arts J, Lee KJ, Sifrim D, Janssens J: Prevalence of acid reflux functional dyspepsia and its association with symptom profile. Gut. 2005; 54 (10): 1370-6.

18. Neumann H, Monkemuller K, Kandulski A, Malfertheiner P: Dyspepsia and IBS symptoms in patients with NERD, ERD and Barrett's esophagus. Dig Dis. 2008; 26(3):243-7.

19. Oustamanolakis P, Tack J. (2012), Dyspepsia - organ versus functional. J Clin Gastroenterol 46: 175-190.

20. Kamolz T, Bammer T, Pasiut M, Pointner R: Psycho-physiological aspects of gastroesophageal reflux disease. Psychother Psychosom Med Psychol. 2002; 52(34):159-65.

21. Jung HK, Halder S, McNally M et al. Overlap of gastro-oesophageal reflux disease and irritable bowel syndrome: prevalence and risk factors in the general population. Aliment Pharmacol Ther. 2007, 1;26(3):453-61.

22. van der Velden AW, de Wit NJ, Quartero AO, Grobbee DE, Numans ME: Maintenance treatment for GERD: residual symptoms are associated with psychological distress. Digestion. 2008; 77(3-4):207-13.

23. Van Oudenhove L, Vandenberghe J, Geeraerts B et al. Determinants of symptoms in functional dyspepsia: gastric sensorimotor function, psychiological factors or somatisation ? Gut, 2008; 57(12): 1666-73. 
24. Pandolfino JE, Ghosh SK, Rice J, et al. Classifying esophageal motility by pressure topography characteristics: a study of 400 patients an 75 contols. Am J Gastroenterol. 2008;103:27-37.

25. Savarino E, Tutuian $\mathrm{R}$, Zentilin $\mathrm{P}$ et al. Characteristics of reflux episodes and symptom association in patients with erosive esophagitis and nonerosive reflux disease: study using combined impedance-pH off therapy. Am J Gastroenterol 2010, 105: 1053-61.

26. Kellner R: Psychosomatic syndromes, somatization and somatoform disorders. Psychother Psychosom. 1994; 61(1-2):4-24.

27. Rief W, Heuser J, Mayrhuber E, Stelzer I, Hiller W, Fichter MM: The classification of multiple somatoform symptoms. J Nerv Ment Dis. 1996;184(11):6807.

28. Rief W, Hiller W, Heuser J: SOMS- Das Screening für Somatoforme Störungen. Manual zum Fragebogen. Bern, Huber Verlag; 1997

29. Rief W, Hiller W: Toward empirically based criteria for the classification of somatoform disorders. J Psychosom Res. 1999; 46(6):507-18.

30. Rief W, Hessel A, Braehler E: Somatization symptoms and hypochondriacal features in the general population. Psychosom Med. 2001; 63(4):595-602.

31. Rief W, Hiller W: A new approach to the assessment of the treatment effects of somatoform disorders. Psychosomatics. 2003; ;44(6):492-8.

32. Fink P: Surgery and medical treatment in persistent somatizing patients. J Psychosom Res. 1992; ;36(5):439-47

33. Mussell M, Kroenke K, Spitzer RL, Williams JB, Herzog W, Löwe B. Gastrointestinal symptoms in primary care: prevalence and association with depression and anxiety. J Psychosom Res 2008; 64 (6): 605-12.

34. Löwe B, Spitzer RL, Williams JB, Mussell M, Schellberg D, Kroenke K. Depression, anxiety and somatization in primary care: syndrome overlap and functional impairment. Gen Hosp Psychiatry 2008; 30(3): 191-9.

35. Cheville AL, Basford JR, Dos Santos K, Kroenke K. Symptom burden and comorbidities impact the consistency of responses on patient-reported functional outcome. Arch Phys Med Rehabil, 2014; 95(1): 79-86.

36. Diagnostic and Statistical Manual of Mental Disorders, $5^{\text {th }}$ Edition. www.dsm5.org/pages/Default.aspx. Accessed 01/28/2015.

37. Kamolz T, Granderath FA, Bammer T, Pasiut M, Pointner R: Psychological intervention influences the outcome of laparoscopic antireflux surgery in patients with 
stress-related symptoms of gastroesophageal reflux disease. Scand J Gastroenterol. 2001; 36(8):800-5.

38. Velanovich V, Karmy-Jones R: Psychiatric disorders affect outcomes of antireflux operations for gastroesophageal reflux disease. Surg Endosc. 2001;15(2):171-5.

39. Mearin F, Ponce J, Ponce M, Balboa A, Gónzalez MA, Zapardiel J: Frequency and clinical implications of supraesophageal and dyspeptic symptoms in gastroesophageal reflux disease. Eur J Gastroenterol Hepatol. 2012 Jun; 24 (6): 66574.

40. Kamolz T, Granderath, Pointner R. Laparoscopic antirefluxsurgery: disease-related quality of life assessment before and after surgery in GERD patients with and without Barrett's esophagus. . Surg Endosc 2003;17:880-885.

41. Fein $\mathrm{M}$, Bueter $\mathrm{M}$, Thalheimer $\mathrm{A}$, et al. Ten year outcome of laparoscopic antireflux procedures. J Gastrointest Surg 2008 12: 1893-1899.

42. Eypasch E, Williams JI, Wood DS, et al. Gastrointestinal Quality of Life Index: development, validation and application of a new instrument. Br J Surg 1995;82:216222.

43. Campos GM, Peters JH, DeMeester TR et al. Multivariate analysis of factors predicting outcome after laparoscopic Nissen fundoplication. J Gastrointest Surg 1999;3(3):292-300.

44. Kahrilas PJ, Jonsson A, Denison H, Wernersson B, Hughes N, Howden CW: Regurgitation is less responsive to acid suppression than heartburn in patients with gastroesophageal reflux disease. Clin Gastroenterol Hepatol. 2012 Jun; 10 (6): 612-9.

45. Jaspersen $\mathrm{D}$, Kulig $\mathrm{M}$, Labenz $\mathrm{J}$ et al. Prevalence of extra-oesophageal manifestations in gastro-oesophageal reflux disease: an analysis based on the ProGERD Study. Aliment.Pharmacol Ther 2003; 17:1515-1520.

46. Malhotra A, Freston JW, Aziz K Use of $\mathrm{pH}$-impedance testing to evaluate patients with suspected extraesophageal manifestations of gastroesophageal reflux disease. $\mathrm{J}$ Clin Gastroenterol 2008; 42:271-278.

47. de Bortoli, N, Nacci A, Savarino E et al. How many cases of laryngopharyngeal reflux suspected by laryngoscopy are gastroesophageal reflux disease-related? World $\mathrm{J}$ Gastroenterol 2012; 18:4363-4370.

48. Chang $A B$, Lasserson $T J$, Gaffney $\mathrm{J}$ et al. Gastro-oesophageal reflux treatment for prolonged non-specific cough in children and adults. Cochrane Database Syst Rev 2011; CD004823.

49. Kiljander TO, Junghard O, Beckman O et al. Effect of Esomeprazole $40 \mathrm{mg}$ Once or Twice Daily on Asthma: A Randomized, Placebo-controlled Study. American Journal of Respiratory and Critical Care Medicine 2010; 181:1042-1048. 
50. Smith JA, Decalmer S, Kelsall A et al. Acoustic cough-reflux associations in chronic cough: potential triggers and mechanisms. Gastroenterology 2010; 139:754-762.

51. Savarino E, Carbone R, Marabotto E et al. Gastro-oesophageal reflux and gastric aspiration in idiopathic pulmonary fibrosis patients. Eur Respir J. 2013, 42 (5): 132231.

52. Katz PO, Gerson LB, Vela MF. Guidelines for the Diagnosis and Management of Gastroesophageal Reflux Disease. Gastroenterology 2013; 108:308 - 328.

53. DeGruy F, Columbia L, Dickinson P. Somatization Disorder in a family practice. J Fam Pract 1987; 25(1):45-51.

54. Escobar JI, Burnam MA, Karno M, Forsythe A, Golding JM: Somatization in the community. Arch Gen Psychiatry. 1987 Aug;44(8):713-8.

55. Othmer E, DeSouza C: A screening test for somatization disorder (hysteria). Am J Psychiatry. 1985 Oct;142(10):1146-9.

56. Swartz M, Hughes D, George L, Blazer D, Landerman R, Bucholz K: Developing a screening index for community studies of somatization disorder. J Psychiatr Res. 1986;20(4):335-43.

57. Zaballa P, Crega Y, Grandes G, Peralta C: The Othmer and DeSouza test for screening of somatisation disorder: is it useful in general practice? $\mathrm{Br} \mathrm{J}$ Gen Pract. 2001 Mar;51(464):182-6.

Legends of Figures:

Figure 1: Distribution of symptoms (in \%) in healthy individuals

Figure 2: Comparison of symptom-distribution (in \%) of patients with foregut symptoms between those patients with pathologic esophageal acid exposure (white) versus those with normal acid exposure (black).

Figure 3: Overview on the Somatoform Symptom Index (SSI) of healthy individuals and patients with foregut symptoms (black columns), as well as further subdivided in 
the grey columns (right) in those with and those without pathologic acid exposure as criterion for the presence of GERD.

Figure 4: Comparison of the presence of somatoform tendencies $(\mathrm{SSI}>17)$ in healthy individuals $(5,6 \%)$ compared to patients with foregut symptoms $(19,9 \%)$, demonstrated in 267 unselected healthy volunteers and 651 patients with foregut symptoms.

Figure 5: Comparison of the presence of somatoform tendencies $(\mathrm{SSI}>17)$ in patients without $(20,6 \%)$ and with pathologic acid exposure as criterion of the presence of GERD (19,5\%). 


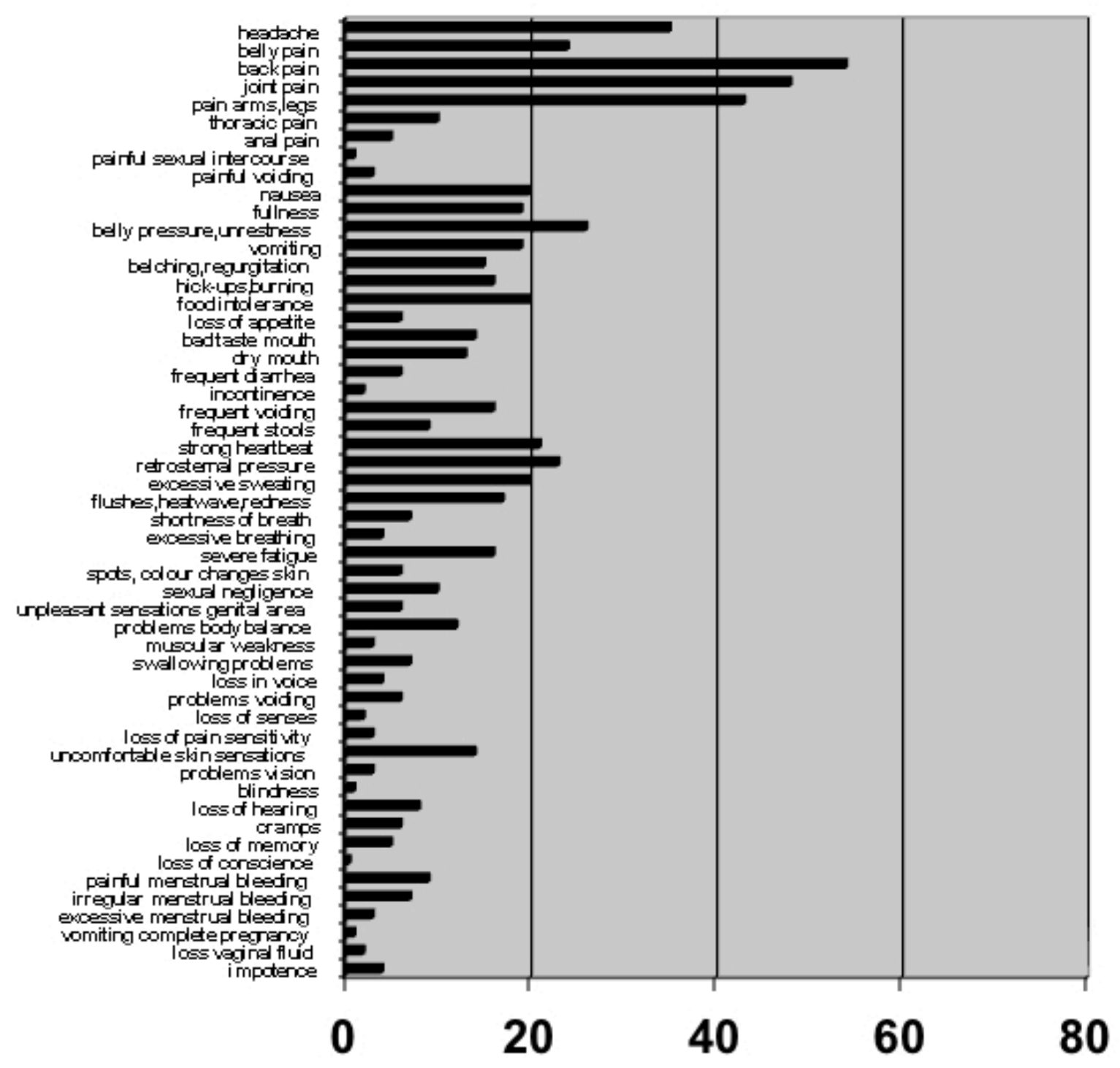

Figure 1: 


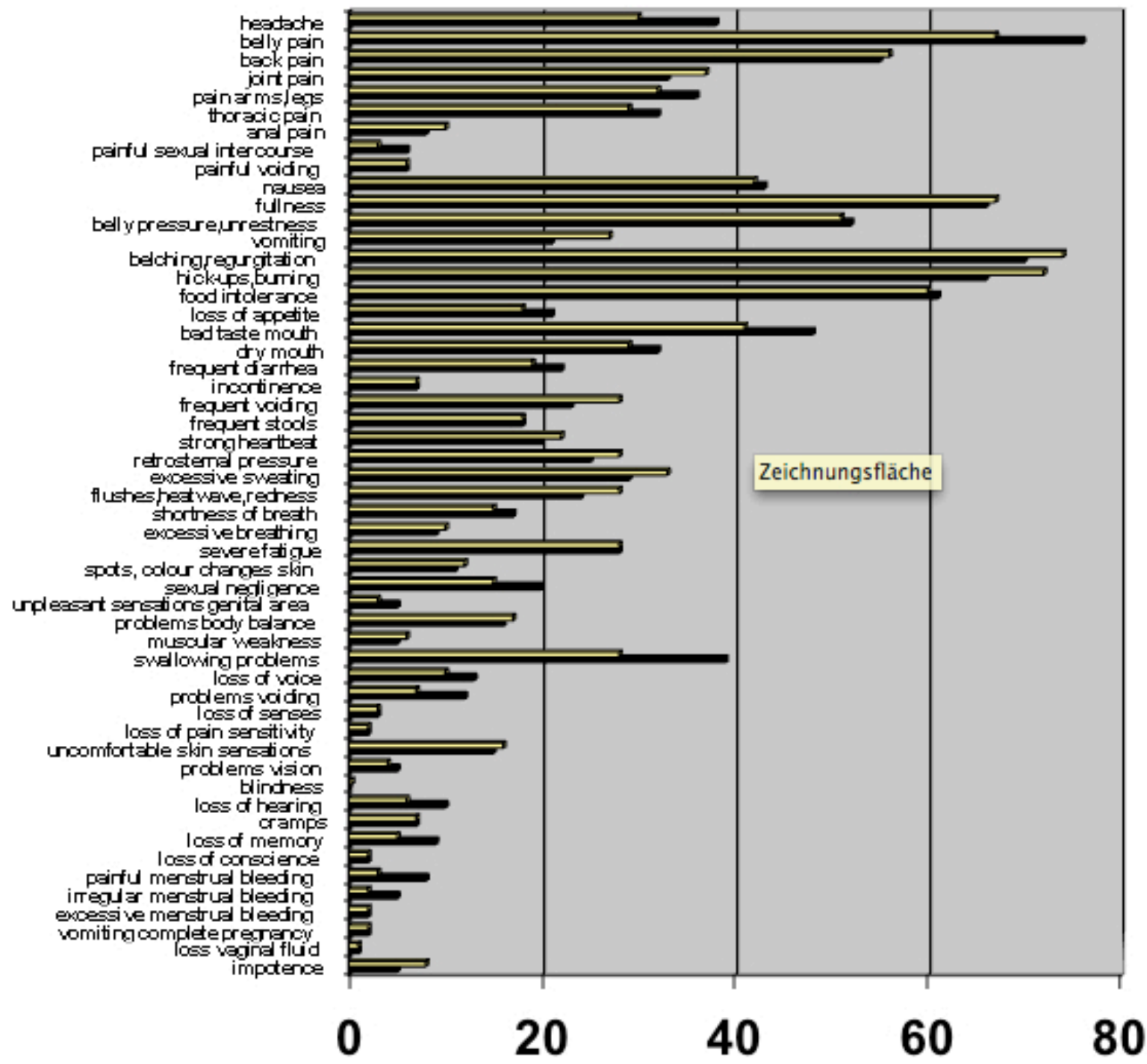

Figure 2: 


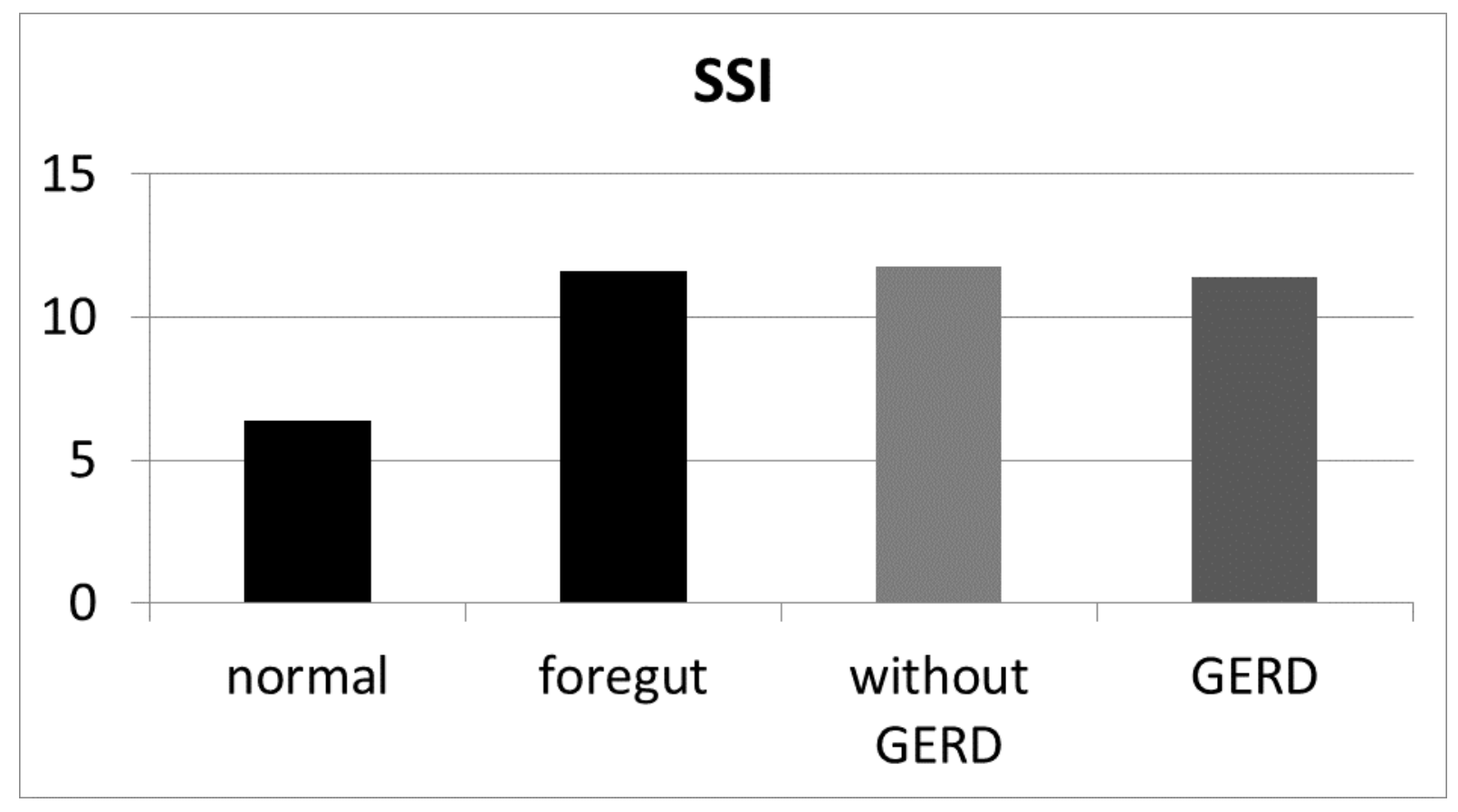

Figure 3:

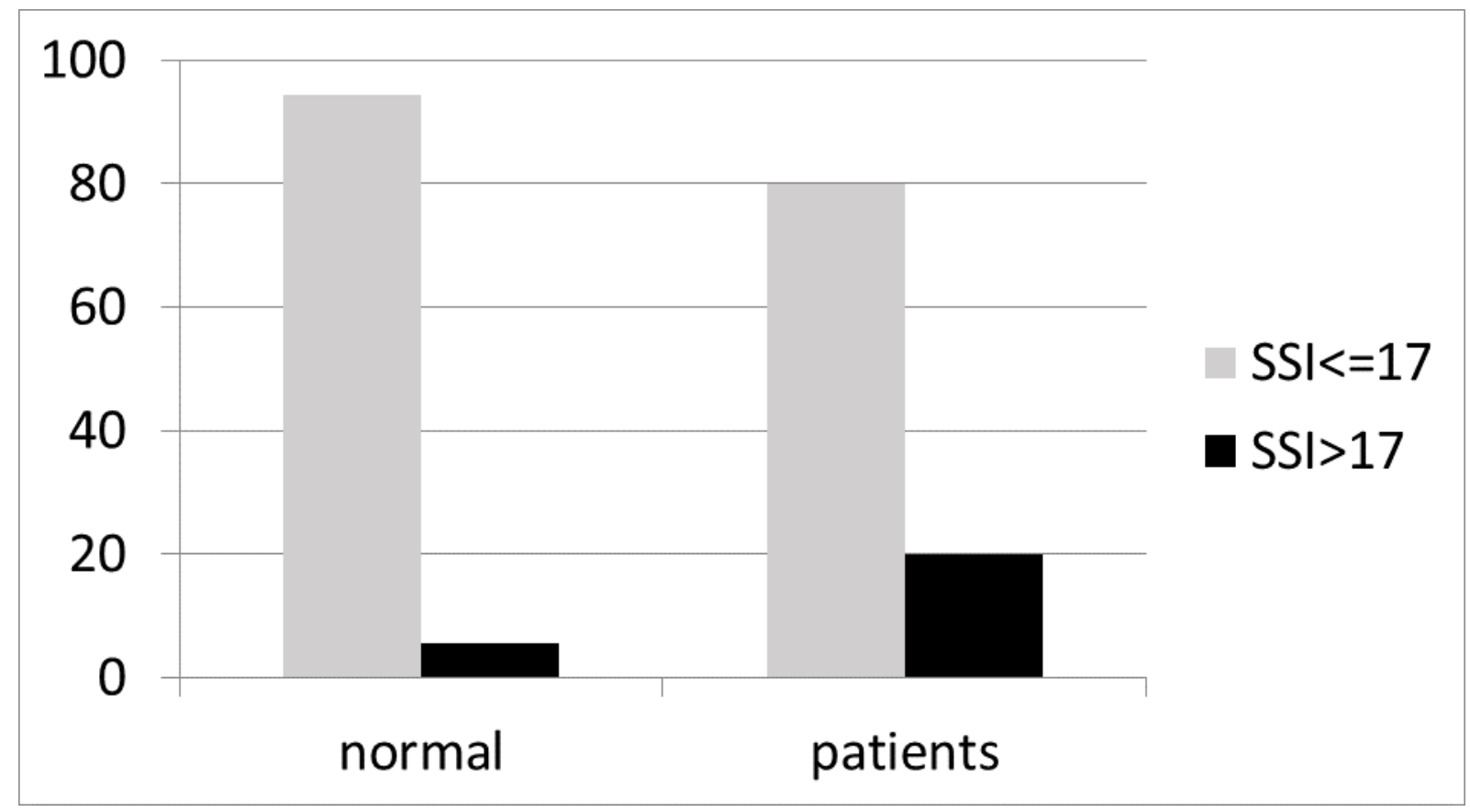

Figure 4: 


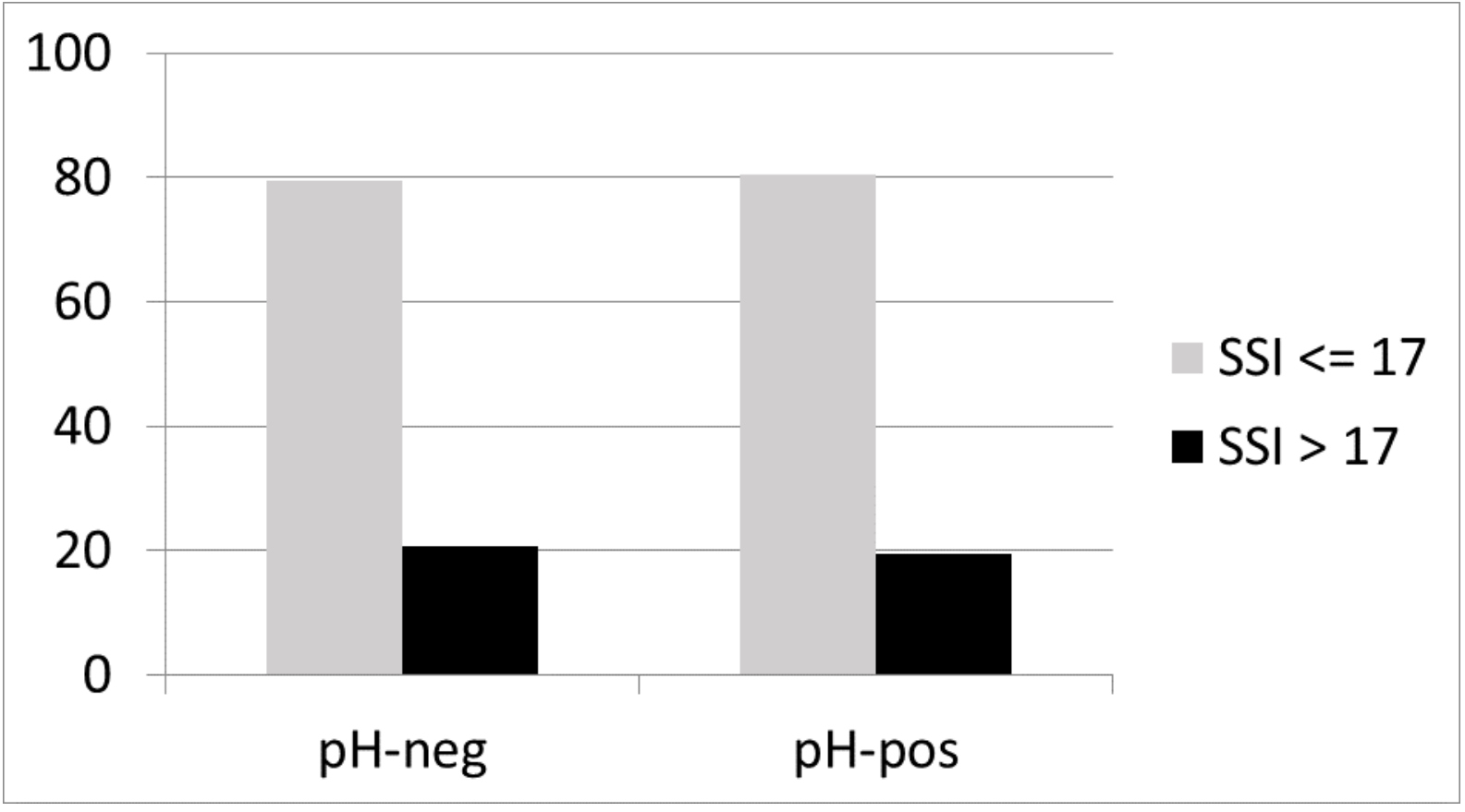

Figure 5: 